\title{
SELEÇÃO DE ALTERNATIVAS DE PROJETO ATRAVÉS DE UM ÍNDICE GLOBAL DE IMPACTOS AMBIENTAIS
}

\author{
PROJECT ALTERNATIVES SELECTION USING AN ENVIRONMENTAL IMPACT GLOBAL \\ INDEX
}

\author{
Adriano BRESSANE ${ }^{1}$, José Arnaldo Frutuoso ROVEDA ${ }^{1}$, Sandra Regina Monteiro \\ Masalskiene ROVEDA ${ }^{1}$, Antonio Cesar Germano MARTINS ${ }^{1}$, Fábio Augusto Gomes Vieira \\ REIS $^{2}$, Lucilia do Carmo GIORDANO ${ }^{2}$ \\ ${ }^{1}$ Universidade Estadual Paulista / UNESP. Sorocaba, São Paulo. Emails: adrianobressane@ymail.com, roveda@sorocaba.unesp.br, \\ sandra@sorocaba.unesp.br, amartins@sorocaba.unesp.br \\ 2Universidade Estadual Paulista / UNESP. Rio Claro, São Paulo. Emails: fabioreis@rc.unesp.br, lcg@ecogeologia.com.br
}

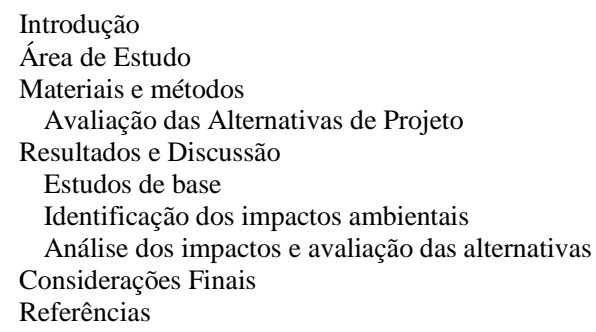

RESUMO - As atividades potencialmente causadoras de degradação estão condicionadas à avaliação de impactos ambientais. Entretanto, a falta de um procedimento lógico estruturado pode prejudicar a análise comparativa dos locais e tecnologias disponíveis. Assim, o objetivo deste artigo foi avaliar o uso de um índice global de impacto (IGI) como proposta metodológica para apoiar decisões relacionadas a seleção entre as alternativas de projeto. Para isso, o índice foi aplicado em um estudo de caso para implantação de uma atividade modificadora do meio ambiente, situada em empreendimento urbanístico do interior paulista. Como resultado, constatou-se que o IGI foi capaz de avaliar criteriosamente as alternativas de projeto, subsidiando de forma direta e sistemática recomendações quanto às tecnologias e locais mais apropriados para o empreendimento em estudo.

Palavras-chave: Modelagem Matemática; Tratamento de Esgoto; Licenciamento Ambiental.

ABSTRACT - Licensing activities that may cause significant degradation depends on the environmental impact assessment. However, the lack of a structured logical procedure can impair comparative analysis of locations and technologies available to the venture. Thus, the aim of this paper was to evaluate the use of a global impact index (IGI) for supporting decision related to the selection among project alternatives. For that, the index was applied in a case study of for the implantation of an impactful activity, within the São Paulo State, Brazil. As a result it was found that the IGI is able to evaluate judiciously the project alternatives, subsidizing direct and systematic recommendations for the technologies and most appropriate locations for the project under study.

Keywords: Mathematical modelling; Sewage treatment; Environmental licensing.

\section{INTRODUÇÃO}

Os impactos ambientais consistem em alterações da qualidade de componentes e processos naturais que, em decorrência das atividades humanas, são capazes de afetar as condições sanitárias, a economia, fauna e flora. Logo, a avaliação de impactos ambientais tornou-se indispensável para apoiar decisões relacionadas a viabilidade de empreendimentos em padrões mais sustentáveis.

Nesse sentido, o licenciamento das atividades modificadoras do meio ambiente está condicionado à análise prévia dos impactos ambientais, considerando a avaliação das alternativas de projeto. Para tanto, diversos têm sido os métodos desenvolvidos, entre os quais podem ser citados os Métodos Ad hoc e Delphi (técnicas espontâneas); Método Batelle (listagem); Métodos de Leopold e de FisherDavies (matrizes); Método IMPACT (redes de interações); Método KSIM (simulação) e Método McHarg (superposição de mapas), entre outros. Contudo, tais métodos foram desenvolvidos em outros países, de modo que:

[...] muitos não são compatíveis com as condições sócio-econômicas e políticas do Brasil, tornando necessárias adaptações, através de modificações e/ ou revisões, para que sejam realmente úteis na tomada de decisão de um projeto (Oliveira \& Moura, 2009).

As normas brasileiras determinam análises para previsão de magnitudes e interpretação da importância dos impactos, discriminando parâmetros para os quais não há orientação quanto ao entendimento, nem tão pouco existe uma padronização para o relacionamento das variáveis (Sánchez, 2006; Carvalho, Reis \& Giordano, 2016).

Logo, o objetivo deste trabalho é avaliar o 
uso de um Índice Global (IGI) como proposta metodológica para apoiar à seleção de alternativas de projeto em estudos de impacto ambiental. Para tanto, o IGI foi aplicado como estudo de caso para implantação de uma atividade modificadora do meio ambiente, na zona de transição da reserva da biosfera da cidade de São Paulo.
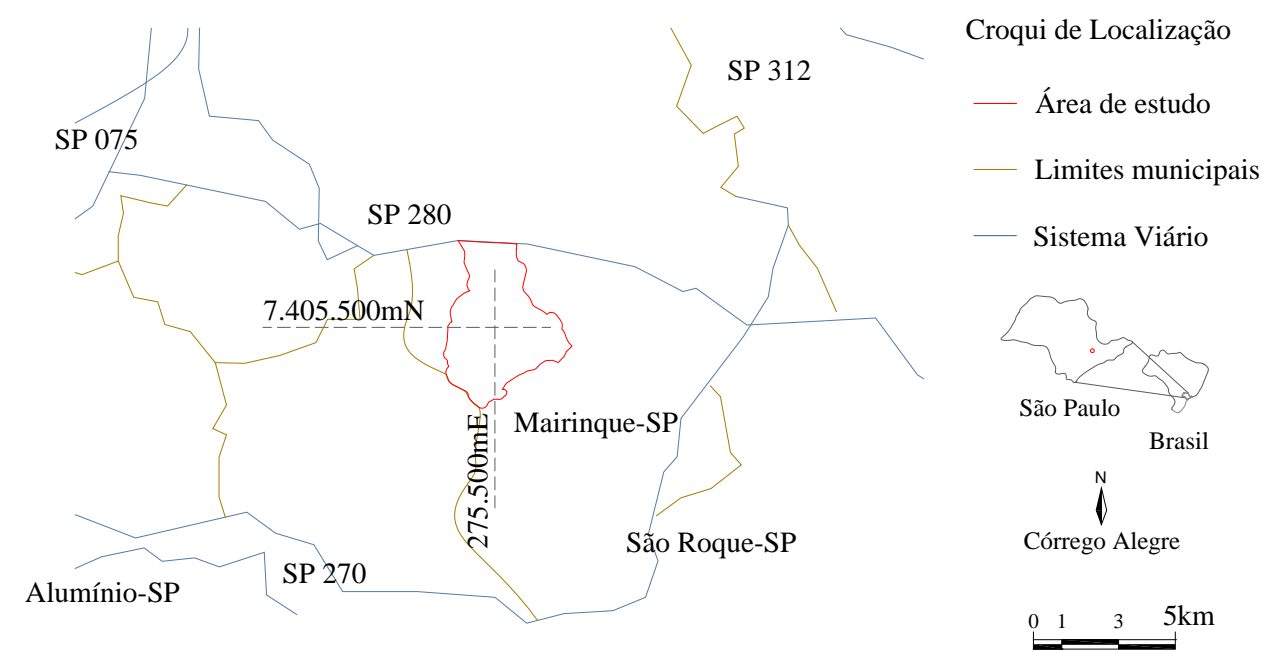

Figura 1 - Localização da área em estudo.

\section{ÁREA DE ESTUDO}

A área de estudo está localizada no setor nordeste de Mairinque (SP), delimitado ao norte pela Rodovia Presidente Castello Branco (SP280) e a leste pela divisa municipal, sob as coordenadas centrais de fuso 23k (MC 51 ${ }^{\circ}$ ) 7.405.500 mN; $275.500 \mathrm{mE}$ (Datum Córrego Alegre) (Figura 1).

Trata-se de uma área de relevante interesse ambiental que integra a Reserva da Biosfera do Cinturão Verde (RBCV) da Cidade de São Paulo. Todavia, o empreendimento está situado na zona de transição na qual é permitido um uso mais intensivo, porém não destrutivo do solo e seus recursos ambientais.

No entorno há importantes Unidades de Conservação da natureza, entre as quais a Área de Proteção Ambiental (APA) de Itupararanga a cerca de $10 \mathrm{~km}$ e a APA de Cabreúva a aproximadamente $7 \mathrm{~km}$ de distância.

Conforme mapeamento realizado sobre a base hidro-cartográfica do Instituto Geográfico e Cartográfico (IGC), calcula-se no interior do empreendimento aproximadamente de 411,7 ha de áreas de preservação permanente constituídas pelas faixas marginais de cursos de água e o entorno da cabeceira de 165 nascentes. A partir da sobreposição desta APP com a delimitação da vegetação sobre imagem aérea, estima-se que cerca de $80 \%$ possui cobertura vegetal (Figura 2).

Considerando a superposição de indicadores ambientais da fauna e flora, na área em estudo a prioridade no incremento de conectividade da vegetação varia de média (classe 4) em regiões tangentes a divisa do empreendimento, a média alta (classe 5) em sua porção central (Rodrigues \& Bononi, 2008).

A área pertence a Unidade de Gerenciamento de Recursos Hídricos dos rios Sorocaba e Médio Tietê (UGRHI 10), sendo sua maior proporção situada na sub-bacia do Médio Tietê Superior e uma pequena extensão a sudoeste interna ao Médio Sorocaba.

A UGRHI 10 possui 133.039 ha de vegetação natural, o equivalente a $11 \%$ de sua superfície. Com base na delimitação realizada sobre fotografia aérea da área, calcula-se cerca de 712,8 ha de cobertura florestal que, segundo o Inventário Florestal do Estado de São Paulo (Kronka et al., 2005), pertence a formação secundária da fisionomia de Floresta Ombrófila Densa Montana.

O clima, pela classificação de Köppen, corresponde ao temperado úmido, caracterizado pelo inverno seco e verão quente (Cwa), com pluviosidade média anual de $1312 \mathrm{~mm}$ e temperatura média anual que alcança $19,3{ }^{\circ} \mathrm{C}$, com média das mínimas em $13,2{ }^{\circ} \mathrm{C}$ e das máximas em $25,4^{\circ} \mathrm{C}$ (CEPAGRI, 2016).

Quanto à disponibilidade potencial para extração de água subterrânea, o empreendimento está situado sobre um aquífero fraturado, com vazão entre 1 a $12 \mathrm{~m}^{3} / \mathrm{h}$ em praticamente todo o empreendimento, e de 3 a $23 \mathrm{~m}^{3} / \mathrm{h}$ no extremo sul da área (Rocha, 2005). 


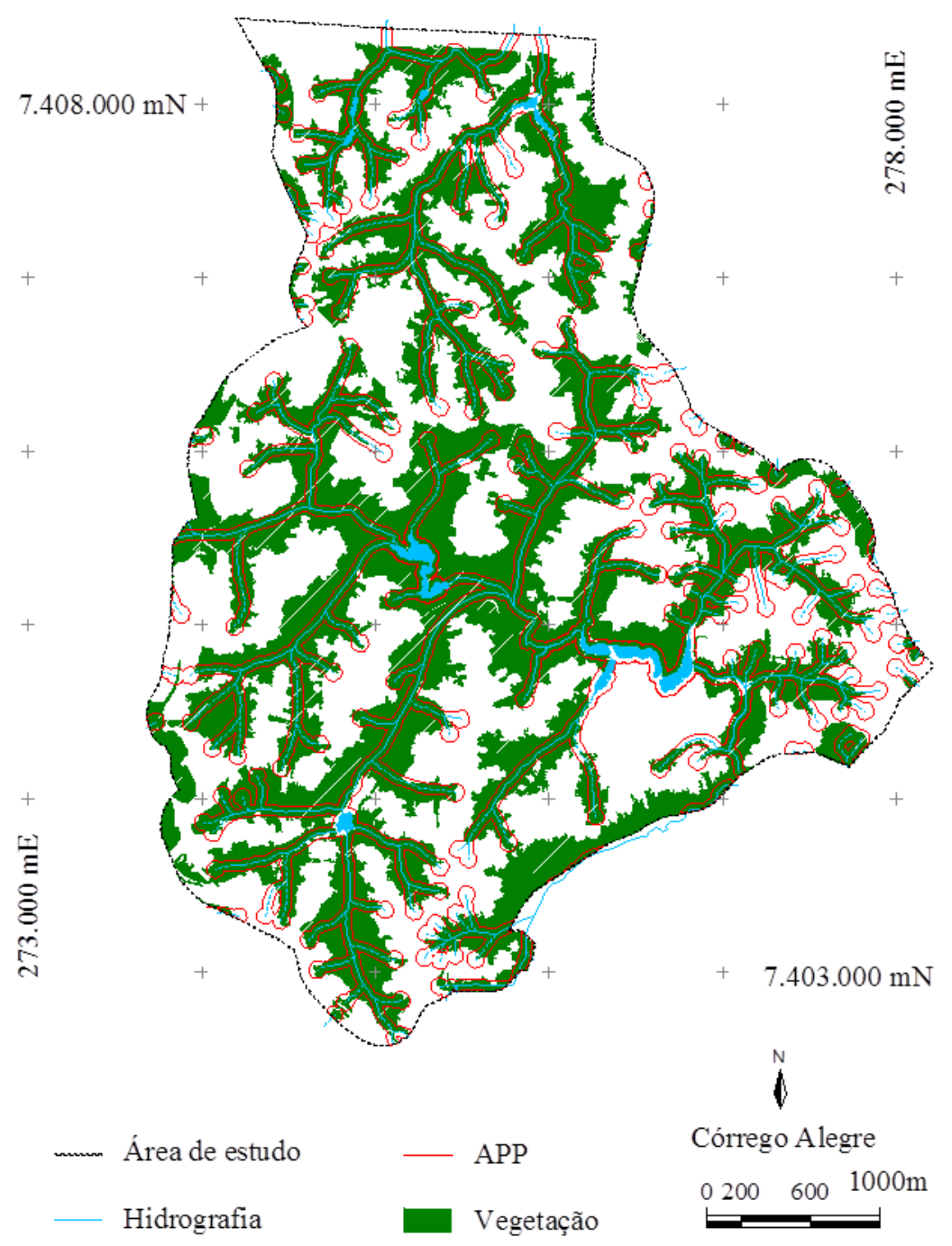

Figura 2 - Condição hidrográfica, cobertura vegetal e áreas de preservação permanente.

A área pertence ao Cinturão Orogênico Atlântico, unidade do Planalto Atlântico, subunidade de Jundiaí.

Nesta subunidade, predominam colinas e morros altos com declividade de 10 a $20 \%$ entre as cotas de 700 a 800 m e 20 a $30 \%$ entre 900 e 1200 m de altitude (Ross \& Moroz, 1997). Conforme a base topográfica do IGC, a altitude na área em estudo varia de valores em torno de $740 \mathrm{~m}$ a até $900 \mathrm{~m}$.

A área pertence predominantemente a Formação Estrada dos Romeiros, composta de arenitos conglomeráticos, metacálcio-pelitos, sedimentos carbonáticos, rochas cálciossilicáticas, quartzitos etc. No entanto, em uma pequena área ao sul do empreendimento ocorre a Formação Piragibu, caracterizada pela presença de arenito, siltito, quartzito e sericita xisto entre outros minerais (CPRM, 2016).

Em toda a área do empreendimento ocorre à classe dos argissolos, caracterizada pela formação de argila de fácil revolvimento na camada inferior (Oliveira et al., 1999).

Este tipo de solo associado a alta taxa pluviométrica dos climas úmidos e super-úmidos que ocorre na região torna a área com muito alta susceptibilidade à processos erosivos.

A representação cartográfica da caracterização apresentada pode ser vista na figura 3, na qual são destacadas três alternativas locacionais para instalação da atividade modificadora do meio ambiente, identificadas como setor noroeste, centro-leste e sul do empreendimento urbanístico.

Para essas alternativas locacionais, uma síntese da caracterização de atributos relevantes para identificação e análise dos impactos é apresentada na tabela 1, na qual também é apresentada uma classificação conforme valores de referência na literatura (ABGE, 1998; Bensusan, 2006; Braga, 2010; IBGE, 2005; Lepsch, 2002; Monteiro, 1973; Primack \& Rodrigues, 2002; Ross, 2000; Sanchez, 2006; Santos, 2004; Troppmair, 2008). 


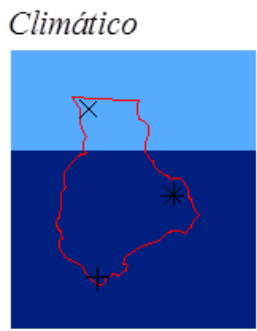

Geomorfológico

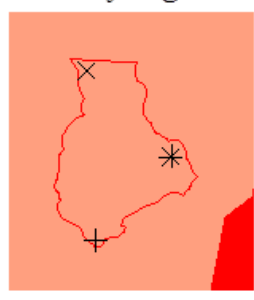

Climático

Tropical Mesotérmico Brando Super Úmido

Tropical Mesotérmico Brando Úmido

Geomorfológico

Planalto Atlântico Paulistano / Alto Tietê

Planalto Atlântico Jundiai

Ecológico

Prioridade média baix a

Prioridade média

Prioridade média alta
Ecológico

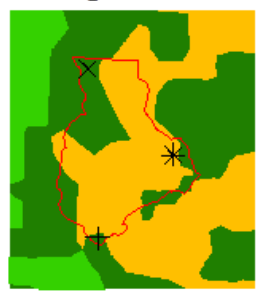

Alternativas locacionais

$\times$ Setor noroeste

* Setor centro-leste

+ Setor sul

-.. Área de estudo

Pedológico
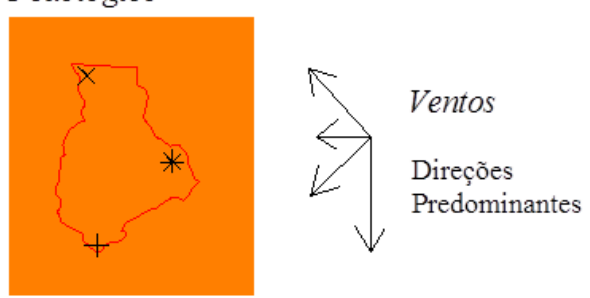

Figura 3 - Alternativas locacionais na área em estudo e seus atributos geoecológicos.

Tabela 1 - Síntese de diagnóstico das alternativas locacionais.

\begin{tabular}{|c|c|c|c|}
\hline $\begin{array}{c}\text { Atributos que } \\
\text { diferenciam as alternativas }\end{array}$ & $\begin{array}{c}\text { Setor Noroeste } \\
(\lambda: 1)\end{array}$ & $\begin{array}{c}\text { Setor Centro-Leste } \\
(\lambda: 2)\end{array}$ & $\begin{array}{c}\text { Setor Sul } \\
(\lambda: 3)\end{array}$ \\
\hline Textura Pedológica & Argilosa & Arenosa média & Argilo-arenosa \\
\hline Capacidade de Troca de Cátion & Maior $\left(87 \mathrm{mmolc} / \mathrm{dcm}^{3}\right)$ & Média $\left(35 \mathrm{mmolc} / \mathrm{dcm}^{3}\right)$ & Menor $\left(26 \mathrm{mmolc} / \mathrm{dcm}^{3}\right)$ \\
\hline Formação Geológica & Sedimentar & Sedimentar & Sedimentar \\
\hline Profundidade do NA* & Média (5-15 m) & Média (5-15 m) & Baixa $(<5 \mathrm{~m})$ \\
\hline Condutividade hidráulica & Baixa $\left(<10^{-8} \mathrm{~cm} / \mathrm{s}\right)$ & Baixa $\left(<10^{-8} \mathrm{~cm} / \mathrm{s}\right)$ & Média $\left(10^{-8}-10^{-5} \mathrm{~cm} / \mathrm{s}\right)$ \\
\hline Condição litológica & Sem fraturas & Sem fraturas & Fraturado \\
\hline Situação topográfica/ cota & Suave ondulado / $740 \mathrm{~m}$ & Ondulado / 830 m & Ondulado / 910 m \\
\hline Declividade média local & Baixa $(<5 \%)$ & Alta $(>20 \%)$ & Média (5-20 \%) \\
\hline Índice pluviométrico anual & Baixo $(<500 \mathrm{~mm})$ & Médio (500-1500 mm) & Alto $(>1500 \mathrm{~mm})$ \\
\hline Direção dos ventos & Desfavorável ** & Muito Desfavorável & Favorável \\
\hline Conservação da vegetação & Sem vegetação & Estágio Médio & Estágio Inicial \\
\hline Ocorrência de fauna & Ausente & Média biodiversidade & Média biodiversidade \\
\hline Recuperação ambiental & Prioridade Média & Prioridade Média-Alta & Prioridade Média \\
\hline Densidade de drenagem & Baixa $\left(<5 \mathrm{~km} / \mathrm{km}^{2}\right)$ & Alto $\left(>15 \mathrm{~km} / \mathrm{km}^{2}\right)$ & Média (5-15 km/km²) \\
\hline Proximidade urbana & Ruim $(<1$ km) & Razoável (1-3 km) & Boa $(>3$ km) \\
\hline
\end{tabular}

* NA - nível freático; ** Predominante em direção a concentração populacional; L: Localização. 


\section{MATERIAIS E MÉTODOS}

\section{Avaliação das Alternativas de Projeto}

No desenvolvimento deste estudo os principais materiais utilizados corresponderam a obras da literatura e normas da legislação aplicável, com base nas quais foram levantados os dados de caracterização das alternativas tecnologias e locacionais.

Na sequência, a avaliação das alternativas de projeto foi realizada através de um índice global de impacto (IGI) adiante descrito, que baseia-se na sistematização de operações matemáticas abrangendo ponderações de Magnitude $(\mu)$ e Importância ( $\iota$, cujo equacionamento resulta na Significância $(\sigma)$ do impacto.

O IGI foi proposto por Bressane et al. (2016) para uma avaliação comparativa de impactos ambientais decorrentes da manutenção e desfazimento de obras irregulares, de modo que foi originalmente desenvolvido para orientar à adequação de obras existentes de forma irregular.

Em contraste, no presente estudo o uso do IGI é avaliado quanto à sua capacidade de apoiar a seleção de alternativas de projeto, previamente a implantação de atividades modificadoras do meio ambiente, isto é, estimar a significância de impactos de diferentes combinações de alternativas tecnológicas e locacionais.

O IGI foi modelado de modo que os critérios de duração, extensão e intensidade correspondem à ponderadores da magnitude dos impactos e, por sua vez, a acumulação, reversibilidade e a sensibilidade são aplicadas como ponderadores da sua importância. Para isso, tais parâmetros são classificados conforme apresentado na tabela 2.

Tabela 2 - Parâmetros ponderados do Índice Global de Impacto.

\begin{tabular}{|c|c|c|c|}
\hline Parâmetro & Ponderador $\left(p_{j}\right)$ & $\begin{array}{l}\text { Modificador } \\
\left(m_{k j}\right)\end{array}$ & $\begin{array}{l}\text { Peso } \\
\left(w_{k j}\right)\end{array}$ \\
\hline \multirow{9}{*}{$\begin{array}{l}\text { Magnitude } \\
(\mu)\end{array}$} & \multirow{3}{*}{$\begin{array}{l}\text { Duração }\left(p_{1}\right) \text { : } \\
\text { tempo de permanência do impacto }\end{array}$} & Curta a Média $\left(m_{11}\right)$ & $1 / 9\left(w_{11}\right)$ \\
\hline & & Longo Prazo $\left(m_{21}\right)$ & $2 / 9\left(w_{21}\right)$ \\
\hline & & Permanente $\left(m_{31}\right)$ & $3 / 9\left(w_{31}\right)$ \\
\hline & \multirow{3}{*}{$\begin{array}{l}\text { Extensão }\left(p_{2}\right) \text { : } \\
\text { abrangência espacial do impacto }\end{array}$} & Pontual $\left(m_{12}\right)$ & $1 / 9\left(w_{12}\right)$ \\
\hline & & Local $\left(m_{22}\right)$ & $2 / 9\left(w_{22}\right)$ \\
\hline & & Regional $\left(m_{32}\right)$ & $3 / 9\left(w_{32}\right)$ \\
\hline & \multirow{3}{*}{$\begin{array}{l}\text { Intensidade }\left(p_{3}\right) \text { : } \\
\text { grau de modificação dos atributos ambientais }\end{array}$} & Baixa $\left(m_{13}\right)$ & $1 / 9\left(w_{13}\right)$ \\
\hline & & Média $\left(m_{23}\right)$ & $2 / 9\left(w_{23}\right)$ \\
\hline & & Alta $\left(m_{33}\right)$ & $3 / 9\left(w_{33}\right)$ \\
\hline \multirow{9}{*}{ (i) Importância } & \multirow{3}{*}{$\begin{array}{l}\text { Acumulação }\left(p_{4}\right) \text { : } \\
\text { melhoria ou agravamento das alterações }\end{array}$} & Ausente $\left(m_{44}\right)$ & $0 / 9\left(w_{44}\right)$ \\
\hline & & Incerta $\left(m_{54}\right)$ & $2 / 9\left(w_{54}\right)$ \\
\hline & & Presente $\left(m_{64}\right)$ & $3 / 9\left(w_{64}\right)$ \\
\hline & \multirow{3}{*}{$\begin{array}{l}\text { Reversibilidade }\left(p_{5}\right) \text { : } \\
\text { capacidade de retorno à uma situação de pré-distúrbio }\end{array}$} & $\operatorname{Sim}\left(m_{45}\right)$ & $1 / 9\left(w_{45}\right)$ \\
\hline & & Talvez $\left(m_{55}\right)$ & $2 / 9\left(w_{55}\right)$ \\
\hline & & Não $\left(m_{56}\right)$ & $3 / 9\left(w_{65}\right)$ \\
\hline & \multirow{3}{*}{$\begin{array}{l}\text { Sensibilidade }\left(p_{6}\right) \text { : } \\
\text { tolerância a alterações nos atributos ambientais }\end{array}$} & Nula $\left(m_{46}\right)$ & $0 \quad\left(w_{46}\right)$ \\
\hline & & Parcial $\left(m_{56}\right)$ & $2 / 9\left(w_{56}\right)$ \\
\hline & & Total $\left(m_{66}\right)$ & $3 / 9\left(w_{66}\right)$ \\
\hline
\end{tabular}

Fonte: modificado de Bressane et al. (2006).

Dessa forma, enquanto os ponderadores $\left(p_{j}\right)$ quantificam a magnitude $(\mu)$ do impacto $\mathrm{e}$ qualificam sua importância $(\iota)$, os modificadores $\left(m_{k j}\right)$ correspondem as classes que caracterizam a condição avaliada para cada um destes parâmetros, segundo a qual são atribuídos os pesos $\left(w_{k j}\right)$.

As escalas de valores atribuídos a tais pesos foram definidas de modo a limitar um intervalo de variação conveniente para o índice global de impacto entre [-1,1] e assim facilitar uma avaliação comparativa entre as alternativas avaliadas.

Considerando que os impactos podem ter natureza positiva (benéfica) ou negativa (prejudicial), os limiares inferior (-1) e superior (1) representam a pior e a melhor alternativa de projeto, avaliadas segundo (Equações 1 a 7): 


$$
i g i=\frac{1}{n} \sum_{i=1}^{n} \sigma_{i}
$$

onde

igi - índice global de impacto para a alternativa avaliada

$i \quad$ - impacto $(1,2, \ldots, n)$

$n$ - número total de impactos

$\sigma_{i}$ - significância do impacto $i$

onde

$$
\sigma_{i}=\mu_{i} \cdot \iota_{i}
$$

$\mu_{i} \quad$ - magnitude do impacto $i$

$\iota_{i}$ - importância do impacto $i$

onde

$$
\mu_{i}=\sum_{j=1}^{3}\left(p_{j}\right)_{i}
$$

e

$$
\iota_{i}=\sum_{j=4}^{6}\left(p_{j}\right)_{i}
$$

onde

$\left(p_{j}\right)_{i}$ valor do ponderador $j$ para o impacto $i$ onde, para magnitude

$$
\left(p_{j}\right)_{i}=\sum_{k=1}^{3}\left(w_{k j} \cdot m_{k j}\right)_{i}
$$

e para importância

$$
\left(p_{j}\right)_{i}=\sum_{k=4}^{6}\left(w_{k j} \cdot m_{k j}\right)_{i}
$$

onde

$\left(w_{k j}\right)_{i}$ peso do modificador $k$ pertencente ao ponderador $j$ para o impacto $i$, conforme valores propostos na tabela 2.

$\left(m_{k j}\right)_{i}$ valor do modificador $k$ pertencente ao ponderador $j$ para o impacto $i$, o qual representa a condição avaliada para o impacto segundo cada ponderador, dado por:

$$
\left(m_{k j}\right)_{i}=\left\{\begin{array}{c}
1, \text { se pertence a condição avaliada } \\
-1, \text { se a condição está relacionada a } \\
\text { magnitude e o impacto é prejudicial } \\
0, \text { caso contrário }
\end{array}\right.
$$

Com base nestas definições, e (Equações 8 e 9):

$$
\mathbf{M}=\left[\begin{array}{llll}
\mu_{1} & \mu_{2} & \ldots & \mu_{n}
\end{array}\right]
$$

onde

$$
\mathbf{I}=\left[\begin{array}{llll}
\iota_{1} & \iota_{2} & \ldots & \iota_{n}
\end{array}\right]
$$

M - vetor de magnitude dos impactos

I - vetor de importância dos impactos tem-se que o igi determinável por (Equação 10):

$$
i g i=\frac{1}{n} \sum_{i=1}^{n} \sigma_{i}=\frac{1}{n} \sum_{i=1}^{n} \mathrm{M}_{i} \mathrm{I}_{i}=\frac{1}{n}\left(\mathbf{M} . \mathbf{I}^{\mathrm{T}}\right)
$$

Considerando uma análise comparativa entre duas ou mais alternativas de projeto, tem-se o igi para cada uma entre as avaliadas, conforme (Equação 11):

$$
i g i_{\lambda \tau}=\left(\frac{1}{n} \sum_{i=1}^{n}\left(\sigma_{i}\right)_{\lambda \tau}\right)=\left(\frac{1}{n} \sum_{i=1}^{\mathrm{n}}\left(\mathbf{M}_{i \lambda \tau} \cdot \mathbf{I}_{i \lambda \tau}\right)\right)
$$

onde

$i g i_{\lambda \tau^{-}}$índice global de impacto da alternativa de projeto $\left(A_{\lambda \tau}\right)$ composta pela tecnologia $\tau$ associada a localização $\lambda$;

$\lambda=(1,2, \ldots, l)$, onde $l$ é o número total de alternativas locacionais avaliadas;

$\tau=(1,2, \ldots, t)$, onde $t$ é o número total de alternativas tecnológicas avaliadas; e

Logo, para efeito de organização dos dados, temos o vetor dado em (Equação 12):

$$
\left.\boldsymbol{I} \boldsymbol{G} \boldsymbol{I}=\delta_{\lambda \tau}\left(\frac{1}{n}\left(\mathbf{M}_{\lambda \tau} \cdot\left[\mathbf{I}_{\lambda \tau}\right]^{\mathrm{T}}\right)\right)=i g i_{11} i g i_{12} \ldots i g i_{l t}\right]
$$

onde

IGI - matriz composta pelos índices globais de impacto de cada cenário avaliado; e

$\delta_{\lambda \tau}$ - distribuição delta de Dirac, definida como (Equação 13):

$$
\delta_{\lambda \tau}=\left\{\begin{array}{l}
1 \text { se } \lambda=\tau \\
0 \text { caso contrário }
\end{array}\right.
$$

Desse modo, a melhor alternativa de projeto $A_{\lambda / \tau}$, entre as avaliadas será aquela com maior igi (impactos mais positivos ou menos negativos), dada por (Equação 14):

$$
A_{\lambda^{\prime} \tau^{\prime}}=\max (\boldsymbol{I} \boldsymbol{G I})
$$

onde:

$\lambda^{\prime}$ - melhor alternativa locacional (menos sensível aos impactos por $\tau^{\prime}$ )

$\tau^{\prime}$ - melhor alternativa tecnológica (menos severa na geração de impactos sobre $\lambda^{\prime}$ ). 


\section{RESULTADOS E DISCUSSÃO}

\section{Estudos de Base}

Para avaliar a aplicabilidade o IGI, como atividade modificadora do meio ambiente foi estudada a implantação de uma estação de tratamento de esgoto, considerado uma entre as principais causas de degradação ambiental (Scalize et al., 2003).

Para sanear o esgoto sanitário têm sido desenvolvidas diversas tecnologias capazes de acelerar o processo de degradação e estabilização através de estações de tratamento (ETE).

No entanto, mesmo que destinada ao controle da poluição ambiental, a ETE também pode provocar impactos, cuja significância depende de suas alternativas tecnológicas e locacionais.

Assim, três alternativas tecnológicas e três alternativas locacionais para implantação de uma ETE de médio porte foram consideradas, gerando nove cenários hipotéticos que foram avaliados comparativamente como alternativas de projeto através do IGI.

De modo geral, a escolha entre as diversas alternativas disponíveis para tratamento de esgotos é ampla e depende de vários fatores (Ramos, 2004): área disponível para implantação da ETE; topografia dos locais de implantação e das bacias de drenagem das redes de esgotamento sanitário; volumes diários e variações horárias e sazonais das vazões; as características do corpo receptor; custos operacionais; consumo de energia elétrica; clima e variabilidade térmica etc.

Considerando a variabilidade tecnológica aplicável aos processos de tratamento de esgoto, para a seleção de três alternativas para fins comparativos foram consideradas aquelas mais comumente empregadas (CETESB, 1989), sendo as quais:

-Lagoa de Estabilização (Facultativo), tratamento por microorganismos através de fermentação anaeróbia, oxidação aeróbia e redução fotossintética das algas;

-Lodo Ativado (Aeróbio), tratamento por alta concentração, suspensão e recirculação de microbiana através de oxidação aeróbia com uso de aeradores mecanizados; e

-Reator UASB (Upflow Anaerobic Sludge Blanket), tratamento por microrganismos através de fermentação anaeróbia em compartimento fechado.

Considerando os aspectos citados, tais alternativas foram caracterizadas de acordo com referências da literatura técnica (Naval et al., 2004; CETESB, 1989; Vaz \& Ducatti, 2003; Von Sperling, 1996), resumido na tabela 3.

Tabela 3 - Síntese de caracterização das alternativas tecnológicas $(\tau)$.

\begin{tabular}{l|c|c|c}
\hline \multicolumn{1}{c|}{ Aspectos ambientais } & $\begin{array}{c}\text { Lagoa de Estabilização } \\
(\tau: 1)\end{array}$ & $\begin{array}{c}\text { Lodo Ativado } \\
(\tau: 2)\end{array}$ & $\begin{array}{c}\text { Reator UASB } \\
(\tau: 3)\end{array}$ \\
\hline Área ocupada & Grande & Média & Pequena \\
\hline Consumo energético & Baixo & Alto & Baixo \\
\hline Geração de lodo a ser disposto & Baixo & Alto & Baixo \\
\hline Geração de Odores & Significativa & Ausente & Muito significativa \\
\hline Emissão de ruídos & Insignificante & Significativa & Pouco significativa \\
\hline Tempo médio de processo & Lento & Rápido & Médio \\
\hline Remoção de Matéria Orgânica & Média & Alta & Alta \\
\hline Remoção de Nutrientes & Relativa** & Relativa** & Insignificante \\
\hline Custos (implantação e operação)* & Baixo & Alto & Baixo \\
\hline Necessidade de Mão de Obra & Eventual & Eventual & Constante \\
\hline Especialização da Mão de Obra & Inferior & Intermediário & Maior \\
\hline
\end{tabular}

* Relativos a tecnologia e área ocupada; ** Há possibilidade de ocorrer; T: Tecnologia.

Para finalidade deste estudo, os aspectos apresentados foram definidos como diferenciais tecnológicos e, assim, outros parâmetros como variáveis da população, características dos esgotos gerados, qualidade do corpo hídrico receptor, relativas aos canais de coleta e afastamento das águas brutas e tratadas, processos primários e terciários, quando 
necessários, foram considerados como fatores comuns para todas as alternativas.

\section{Identificação dos Impactos Ambientais}

Os impactos ambientais da implantação e operação de uma estação de tratamento de esgoto são determinados por um conjunto de aspectos relacionados com a sua tecnologia e atributos da localização, discutidos a seguir.

Em geral, a contratação de recursos humanos para implantação e operação do empreendimento provoca aumento na demanda local por mão-de-obra, impactando de forma positiva (natureza), com a geração de emprego, renda e respectiva melhoria do nível de vida.

Considerando o padrão médio-alto do empreendimento, apenas alternativas locacionais e/ou tecnológicas que demandam mão de obra-especializada $(\tau: 3)$, têm potencial de impactar os cenários em estudo, pois em outros casos a mão-de-obra será de outras regiões.

Este impacto é temporário na fase de construção, mas permanente para o seu funcionamento (duração). Em ambos os casos, a quantidade de pessoas contratadas (intensidade do impacto) dependerá da tecnologia envolvida, bem como das condições iniciais da localização, que determinará a demanda por adequações.

Como exemplo, podemos citar que o UASB $(\tau: 3)$ exige maior mão-de-obra em, bem como o Setor Noroeste $(\lambda: 1)$ requer contração inferior a das outras localizações, por necessitar de menor correção topográfica e não ter vegetação a ser suprimida.

Outro impacto relacionado ao aspecto financeiro é o custo de implantação e manutenção, o que pode ser reequilibrado (reversibilidade), uma vez que a melhoria nas condições sanitárias reduzirá gastos no setor de saúde.Quanto à supressão da vegetação durante a preparação da área, impacta de forma negativa, permanente e irrecuperável durante a manutenção do empreendimento ao provocar perda de biodiversidade pelo corte da flora e afugentamento fauna.

A intensidade deste impacto dependerá do tamanho da área ocupada, sendo para $\tau: 1>\tau$ : 2 $>\tau: 3$ no caso em análise. Por sua vez, a intolerância quanto às alterações (sensibilidade) depende das condições atuais, sendo maior para áreas com vegetação em estágios mais avançados ( $\lambda: 2)$ em comparação com áreas de mata inicial ( $\lambda: 3)$, pioneira ou mesmo desflorestada $(\lambda: 1)$.

Com a supressão da vegetação também há exposição do solo, mesmo que temporária, favorecendo processos erosivos que impactam com assoreamento de cursos hídricos à jusante, assim como é potencializado pelo movimento de terra durante o nivelamento do terreno.

Da mesma forma, a duração, intensidade e demais ponderadores do impacto estão sujeitos as características tecnológicas e locacionais, tal como a sensibilidade maior em áreas com maior densidade de drenagem $(\lambda: 2)$, grande exposição do solo e desprovidas de mata ciliar $(\lambda: 1)$, mais sujeitas ao transporte de sedimentos para os fundos de vale.

Durante as obras são realizadas operações de escavação e construção das instalações do empreendimento impactando negativamente pela geração de efluentes líquidos, poluentes atmosféricos e resíduos sólidos.

Dependendo da tecnologia, a limpeza de equipamentos, tais como gradeamento, caixas de areia e caixa de gordura, bem como a remoção da escuma de lagoas e capina da área, gera resíduos sólidos minerais e orgânicos acumulados durante tais etapas do tratamento.

Em todos estes casos, pode ocorrer poluição ambiental, cujo potencial de agravamento ou melhoria (acumulação) depende do processo envolvido (tecnologia) com maior $(\tau: 2)$ ou menor ( $\tau: 1$ e $\tau: 3$ ) geração de lodo, bem como da capacidade suporte da área. Em particular, áreas com maior capacidade de troca de cátions $(\lambda: 1)$ tem maior potencial de depuração dos poluentes, gerando uma acumulação menor dos impactos decorrentes.

Assim, conforme a tecnologia adotada, ainda pode ser gerado odor, ocorrer a liberação de gases, a emissão de ruídos, além dos resíduos sólidos, com produção diferenciadas de lodo, que podem causar impactos negativos pelo alto risco de contaminação ambiental.

A poluição sonora e o odor, por exemplo, são menos impactantes nos setores afastados da concentração populacional $(\lambda: 3)$ e/ou onde há vegetação que proporciona uma barreira $(\lambda: 2 \mathrm{e}$ $\lambda: 1)$. Contudo, em relação ao odor, a direção dos ventos é ainda mais relevante, sendo decisiva como agravante nos casos de propagação em direção a população $(\lambda: 2)$.

Outro aspecto relevante é a paisagem sonora, 
isto é, o nível de ruído de fundo, anterior ao empreendimento, pois uma área mais ruidosa próxima a rodovia $(\lambda: 1$,) sofre menor alteração da pressão acústica ambiente.

Por outro lado, a acumulação é afetada por outras fontes do impacto, como o trânsito de veículos, gerador de ruídos e gases de combustão, bem como pela compactação do solo.

No caso da poluição atmosférica, a presença e porte significativos de vegetação $(\lambda: 2)$, pode melhorar a qualidade do ar, além de reduzir a poluição sonora.

Entretanto, as operações de tratamento reduzem o potencial poluidor do esgoto, prevenindo a poluição por sólidos em suspensão, a eutrofização pela remoção de nutrientes, a diminuição de oxigênio dissolvido pela redução da sua demanda e os riscos à saúde pela desinfecção de patógenos, constituindo impactos positivos permanentes.

\section{Análise dos Impactos e Avaliação das Alternativas}

Com fundamento nos estudos de base e identificação dos impactos, na sequência são atribuídos os valores equivalentes a condição avaliada para o caso e alternativas em análise, segundo os parâmetros ponderadores de magnitude e importância.

Como a representação na forma das matrizes tridimensionais $\mathbf{M}_{i \lambda \tau}$ (magnitude) e $\mathbf{I}_{i \lambda \tau}$ (importância) desfavorece a visualização dos dados, tais valores são apresentados na forma tabular nas tabelas 4 e 5 , respectivamente. De acordo com os valores apresentados e pela aplicação da equação 12 temos que:

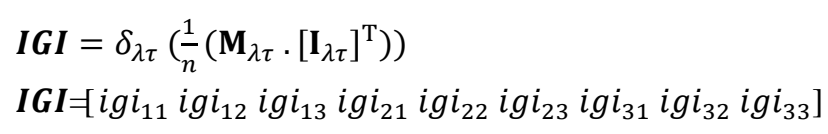

$\boldsymbol{I} \boldsymbol{G} \mathbf{I}=[-0,23-0,26-0,21-0,24-0,27-0,21-0,27-0,21-0,21]$

A partir da equação 13, as melhores alternativas de projeto para o caso em estudo correspondem à:

$A_{\lambda / \tau^{\prime}}=\max (\mathbf{I G I})=\left[\begin{array}{llll}\text { igi }_{13} & \text { igi }_{23} & \text { igi }_{32} & \text { igi }_{33}\end{array}\right]=[-$ $0,21]=A_{13}=A_{23}=A_{32}=A_{33}$

Logo, entre os nove cenários avaliados constata-se que há quatro combinações de tecnologia e localização que podem ser recomendadas como as melhores alternativas de projeto, sendo as quais os cenários compostos pelo reator UASB $(\tau: 3)$ em quaisquer das localizações $(\lambda: 1,2,3)$ e pelo Lodo Ativado $(\tau: 2)$ na região sul $(\lambda: 3)$.

Destaca-se ainda que, apesar do Lodo Ativado $(\tau: 2)$ estar entre as melhores alternativas quando localizado na região sul $(\lambda: 3)$, verifica-se que também está entre as piores opções se instalado na região centro-leste $(\lambda: 2)$, o que ressalta a eficácia da análise integrada entre os aspectos tecnológicos e os atributos locacionais através do IGI.

Apesar do índice não ter resultado em uma única alternativa de projeto, possibilitou identificar cinco cenários que devem ser evitados, apontou a tecnologia mais adequada $(\tau: 3)$ e ainda uma alternativa tecnológica $(\tau: 2)$ caso a região sul $(\lambda: 3)$ seja selecionada.

\section{CONSIDERAÇÕES FINAIS}

$\mathrm{O}$ índice global não visa assegurar a viabilidade ambiental da alternativa melhor avaliada, o que demandaria um estudo quanto à eficiência das medidas de controle aplicáveis a cada caso. No entanto, o IGI proporciona uma análise comparativa que visa apoiar a tomadas de decisão por especialistas.

Neste sentido, observou-se com base no caso estudado que o índice global de impacto apontou que uma mesma tecnologia $(\tau: 2)$ pode estar entre as melhores e piores alternativas dependendo do local para sua implantação e operação.

Da mesma forma, o IGI também possibilitou constatar que uma mesma região $(\lambda: 3)$ pode estar entre as melhores ou piores alternativas locacionais em função da tecnologia considerada ( $\tau: 3$ ou $\tau: 1$, respectivamente) e, ainda, pode demonstrar que a melhor solução não é necessariamente única, como demonstrado nos resultados alcançados.

Pelo exposto, pode-se considerar que o IGI representa uma contribuição metodológica promissora como ferramenta de apoio capaz de subsidiar tecnicamente, de forma direta e sistemática, decisões relacionadas a seleção de alternativas de projeto em processos de licenciamento que dependem da avaliação de impacto ambiental. 
Tabela 4 - Análise dos impactos quanto à condição avaliada para magnitude $\left(\mathbf{M}_{i \lambda \tau}\right)$.

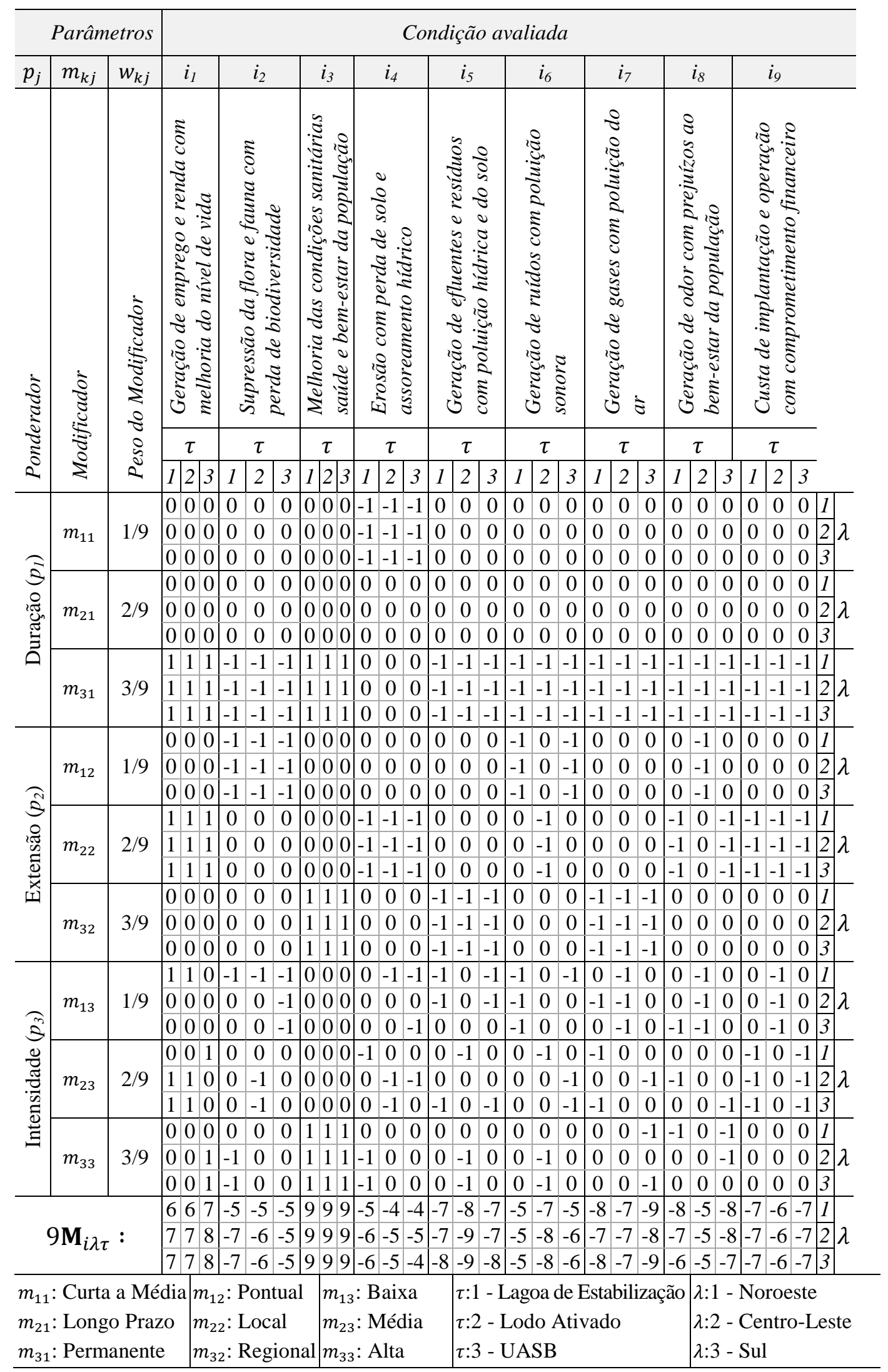


Tabela 5 - Análise dos impactos quanto à condição avaliada para importância $\left(\mathbf{I}_{i \lambda \tau}\right)$.

\begin{tabular}{|c|c|c|c|c|c|c|c|c|c|c|c|c|c|c|c|c|c|c|c|c|c|c|c|c|c|}
\hline \multicolumn{3}{|c|}{ 'arâmetros } & \multicolumn{23}{|c|}{ Condição avaliada } \\
\hline$p_{j}$ & $n_{k i}$ & & $i_{1}$ & & $\mathrm{i}_{2}$ & $i_{2}$ & & $i_{3}$ & & $i_{4}$ & & & $i_{5}$ & & & $i_{6}$ & & $t$ & & & $i_{8}$ & & $i_{9}$ & & \\
\hline \multirow{3}{*}{$\begin{array}{l}\frac{1}{0} \\
\frac{0}{0} \\
\frac{1}{8} \\
\frac{0}{0} \\
0 \\
2\end{array}$} & \multirow{3}{*}{ 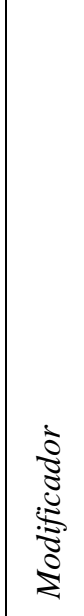 } & \multirow{3}{*}{ 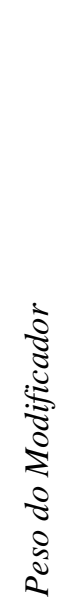 } & \multicolumn{2}{|c|}{ 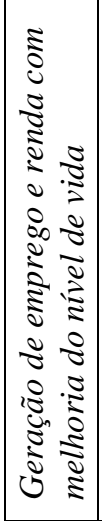 } & \multicolumn{2}{|c|}{ 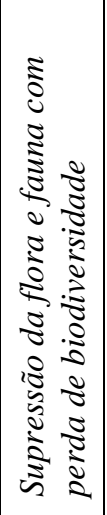 } & \multicolumn{3}{|c|}{ 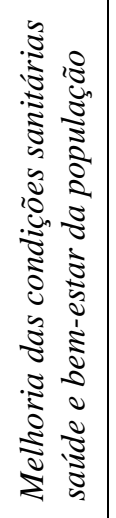 } & \multicolumn{2}{|c|}{ 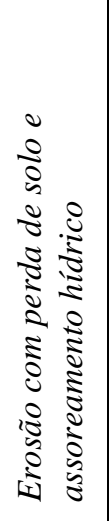 } & \multicolumn{3}{|c|}{ 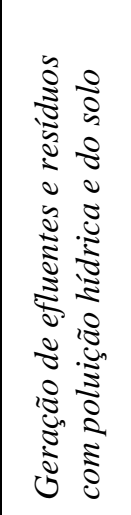 } & \multicolumn{2}{|c|}{ 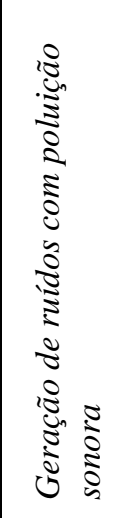 } & \multicolumn{3}{|c|}{ 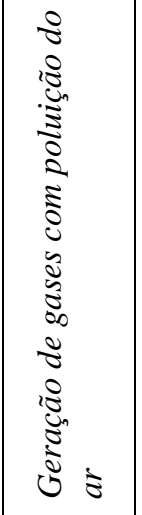 } & \multicolumn{3}{|c|}{ 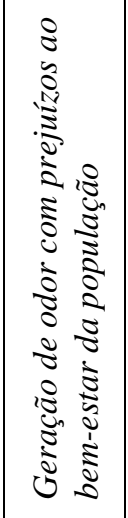 } & \multicolumn{3}{|c|}{ 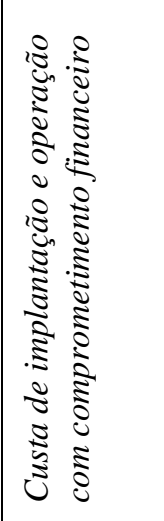 } \\
\hline & & & \multicolumn{2}{|c|}{$\tau$} & \multicolumn{2}{|c|}{$\tau$} & \multicolumn{2}{|r|}{$\tau$} & & $\tau$ & & & $\tau$ & & & $\tau$ & & 0 & & & $\tau$ & & $\tau$ & & \\
\hline & & & 112 & 3 & 12 & 23 & 1 & \begin{tabular}{l|l}
2 & 3 \\
\end{tabular} & 1 & 2 & 3 & 1 & 2 & 3 & 1 & \begin{tabular}{l|l}
2 & 3 \\
\end{tabular} & $3 \quad 1$ & 12 & 3 & 1 & 2 & 3 & 12 & 3 & \\
\hline & & & \begin{tabular}{l|l}
0 & 0 \\
\end{tabular} & 0 & \begin{tabular}{l|l}
1 & 1 \\
\end{tabular} & \begin{tabular}{l|l|}
1 & 1 \\
\end{tabular} & 0 & \begin{tabular}{l|l}
0 & 0 \\
\end{tabular} & 0 & 0 & 1 & 0 & 6 & & 0 & \begin{tabular}{l|l}
0 & 0 \\
\end{tabular} & \begin{tabular}{l|l}
0 & 0
\end{tabular} & 0 & 0 & & 1 & 0 & $\begin{array}{lll}0 & 0 \\
\end{array}$ & \begin{tabular}{l|l}
0 & 1 \\
\end{tabular} & 1 \\
\hline & $m_{4}$ & $1 / 9$ & 00 & 0 & 00 & 00 & 0 & 00 & 0 & 0 & 1 & - & 0 & & 1 & & & & & & 1 & 0 & & 02 & \\
\hline & & & 00 & 0 & 00 & 00 & 0 & 00 & 0 & 0 & 1 & 0 & 0 & & 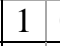 & 0 & & & 0 & & 1 & 0 & $\begin{array}{ll}0 & 0 \\
\end{array}$ & 03 & 3 \\
\hline & & & \begin{tabular}{l|l}
1 & 1 \\
\end{tabular} & 0 & $\begin{array}{lll}0 & 0 \\
\end{array}$ & \begin{tabular}{l|l|}
0 & 0 \\
\end{tabular} & 0 & 0 & 0 & 0 & 0 & 1 & 0 & & 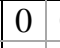 & \begin{tabular}{l|l}
0 & 0 \\
\end{tabular} & & & 0 & & 0 & 0 & \begin{tabular}{|l|l}
1 & 1 \\
\end{tabular} & \begin{tabular}{l|l}
1 & 1 \\
\end{tabular} & 1 \\
\hline & $m_{5}$ & $2 / 9$ & 11 & 0 & 10 & \begin{tabular}{|l|l|}
0 & 0 \\
\end{tabular} & 0 & \begin{tabular}{l|l}
0 & 0 \\
\end{tabular} & \begin{tabular}{l|l|} 
\\
\end{tabular} & 1 & 0 & 0 & 0 & & 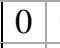 & \begin{tabular}{l|l}
0 & 1 \\
\end{tabular} & & & 1 & í & 0 & 1 & \begin{tabular}{l|l}
1 & 1 \\
\end{tabular} & 12 & 2 \\
\hline 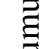 & & & \begin{tabular}{|l|l}
1 & 1 \\
\end{tabular} & 0 & \begin{tabular}{|l|l}
1 & 1 \\
\end{tabular} & \begin{tabular}{|l|l|}
1 & 1 \\
\end{tabular} & 0 & 0 & $\begin{array}{ll}1 \\
\end{array}$ & 1 & & 1 & & & 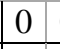 & & & & & & & 1 & \begin{tabular}{l|l}
1 & 1 \\
\end{tabular} & 13 & 3 \\
\hline & & & \begin{tabular}{l|l}
0 & 0
\end{tabular} & 1 & \begin{tabular}{l|l}
0 & 0 \\
\end{tabular} & \begin{tabular}{|l|l|}
0 & 0 \\
\end{tabular} & 1 & \begin{tabular}{l|l}
1 & 1 \\
\end{tabular} & 1 & 1 & 0 & 0 & 1 & & 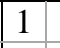 & \begin{tabular}{l|l|}
1 & 1 \\
\end{tabular} & 1 & & 1 & 1 & 0 & 1 & \begin{tabular}{|l|l|}
0 & 0 \\
\end{tabular} & \begin{tabular}{l|l|}
0 & 1 \\
\end{tabular} & 1 \\
\hline & $m_{64}$ & $3 / 9$ & $\begin{array}{lll}0 & 0\end{array}$ & 1 & \begin{tabular}{l|l}
0 & 1
\end{tabular} & \begin{tabular}{|l|l|}
1 & 1 \\
\end{tabular} & 1 & \begin{tabular}{l|l}
1 & 1 \\
\end{tabular} & 0 & 0 & 0 & 0 & 1 & & 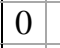 & \begin{tabular}{l|l}
1 & 0 \\
\end{tabular} & 0 & 0 & 0 & 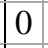 & 0 & 0 & \begin{tabular}{l|l}
0 & 0
\end{tabular} & 02 & 2 \\
\hline & & & \begin{tabular}{|l|l}
0 & 0 \\
\end{tabular} & 1 & $\begin{array}{lll}0 & 0 \\
\end{array}$ & \begin{tabular}{|l|l|}
0 & 0 \\
\end{tabular} & 1 & \begin{tabular}{l|l}
1 & 1 \\
\end{tabular} & 0 & 0 & 0 & 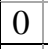 & 1 & & 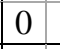 & \begin{tabular}{l|l}
1 & 0 \\
\end{tabular} & 0 & & 0 & & j & 0 & \begin{tabular}{|l|l}
0 & 0 \\
\end{tabular} & $\begin{array}{lll}0 & 3 \\
\end{array}$ & 3 \\
\hline & & & \begin{tabular}{l|l}
0 & 0
\end{tabular} & 0 & \begin{tabular}{l|l}
0 & 0 \\
\end{tabular} & \begin{tabular}{|l|l|}
0 & 0 \\
\end{tabular} & 0 & \begin{tabular}{l|l}
0 & 0 \\
\end{tabular} & \begin{tabular}{l|l|}
0 \\
\end{tabular} & 1 & 1 & $\mathrm{U}$ & & & 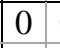 & 0 & 0 & & 0 & & 0 & 0 & \begin{tabular}{|l|l|}
1 & 1 \\
\end{tabular} & \begin{tabular}{l|l|}
1 & 1 \\
\end{tabular} & 1 \\
\hline & & /9 & \begin{tabular}{l|l}
0 & 0
\end{tabular} & 0 & $\begin{array}{lll}0 & 0\end{array}$ & \begin{tabular}{|l|l|}
0 & 0 \\
\end{tabular} & 0 & \begin{tabular}{l|l}
0 & 0
\end{tabular} & 1 & 1 & 1 & 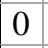 & 0 & & 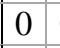 & \begin{tabular}{l|l}
0 & 0 \\
\end{tabular} & 0 & & 0 & & 0 & 0 & \begin{tabular}{l|l}
1 & 1 \\
\end{tabular} & 12 & 2 \\
\hline 3 & & & \begin{tabular}{|l|l}
0 & 0 \\
\end{tabular} & 0 & $\begin{array}{lll}0 & 0 \\
\end{array}$ & \begin{tabular}{|l|l|}
0 & 0 \\
\end{tabular} & 0 & \begin{tabular}{l|l}
0 & 0 \\
\end{tabular} & 1 & 1 & 1 & 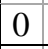 & ( & & 0 & \begin{tabular}{l|l}
0 & 0 \\
\end{tabular} & 0 & & 0 & 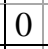 & 0 & 0 & \begin{tabular}{l|l}
111 \\
\end{tabular} & 13 & 3 \\
\hline & & & \begin{tabular}{l|l}
1 & 1
\end{tabular} & 1 & \begin{tabular}{l|l}
0 & 0 \\
\end{tabular} & \begin{tabular}{|l|l|}
0 & 0 \\
\end{tabular} & 1 & \begin{tabular}{l|l}
1 & 1
\end{tabular} & 0 & 0 & 0 & 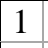 & 1 & & 1 & \begin{tabular}{l|l}
1 & 1
\end{tabular} & 1 & & 1 & & 1 & 1 & \begin{tabular}{|l|l|}
0 & 0 \\
\end{tabular} & \begin{tabular}{l|l}
0 & 1 \\
\end{tabular} & 1 \\
\hline & $m_{55}$ & $/ 9$ & $\begin{array}{ll}1 & 1 \\
\end{array}$ & 1 & $\begin{array}{lll}0 & 0\end{array}$ & $\begin{array}{lll}0 & 0\end{array}$ & 1 & \begin{tabular}{l|l}
1 & 1
\end{tabular} & $\begin{array}{ll}1 & 0 \\
\end{array}$ & 0 & 0 & 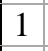 & 1 & & 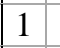 & \begin{tabular}{l|l}
1 & 1 \\
\end{tabular} & 1 & 1 & 1 & 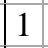 & 1 & 1 & 00 & 02 & $2 \lambda$ \\
\hline & & & \begin{tabular}{|l|l}
1 & 1 \\
\end{tabular} & 1 & $\begin{array}{lll}0 & 0 \\
\end{array}$ & \begin{tabular}{|l|l|}
0 & 0 \\
\end{tabular} & 1 & \begin{tabular}{l|l}
1 & 1 \\
\end{tabular} & 0 & 0 & 0 & $t$ & 1 & & - & \begin{tabular}{l|l}
1 & 1 \\
\end{tabular} & & & 1 & & L & 1 & $\begin{array}{ll}0 & 0 \\
\end{array}$ & $\begin{array}{lll}0 & 3 \\
\end{array}$ & 3 \\
\hline & & & \begin{tabular}{l|l}
0 & 0
\end{tabular} & 0 & \begin{tabular}{|l|l}
1 & 1 \\
\end{tabular} & \begin{tabular}{|l|l|}
1 & 1 \\
\end{tabular} & 0 & \begin{tabular}{l|l}
0 & 0
\end{tabular} & 0 & ) & 0 & 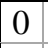 & 0 & & 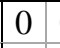 & \begin{tabular}{l|l}
0 & 0
\end{tabular} & 0 & 8 & 0 & 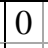 & 0 & 0 & \begin{tabular}{|l|l|}
0 & 0 \\
\end{tabular} & \begin{tabular}{l|l}
0 & 1 \\
\end{tabular} & 1 \\
\hline & $m_{65}$ & 9 & 00 & 0 & $\begin{array}{lll}1 & 1 \\
\end{array}$ & \begin{tabular}{ll|}
1 & 1
\end{tabular} & 0 & $\begin{array}{lll}0 & 0\end{array}$ & 0 & 0 & 0 & 0 & 0 & & 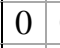 & \begin{tabular}{l|l}
0 & 0 \\
\end{tabular} & 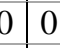 & & 0 & 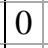 & 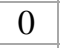 & 0 & $\begin{array}{ll}0 & 0\end{array}$ & 02 & \\
\hline & & & $\begin{array}{lll}0 & 0 \\
\end{array}$ & 0 & \begin{tabular}{|ll}
1 & 1 \\
\end{tabular} & \begin{tabular}{ll|}
1 & 1 \\
\end{tabular} & 0 & \begin{tabular}{l|l}
0 & 0 \\
\end{tabular} & 0 & 0 & 0 & 0 & 0 & & 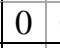 & \begin{tabular}{l|l}
0 & 0 \\
\end{tabular} & 0 & & 0 & 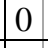 & & 0 & $\begin{array}{lll}0 & 0 \\
\end{array}$ & $\begin{array}{lll}0 & 3 \\
\end{array}$ & 3 \\
\hline & & & $\begin{array}{lll}1 & 1 \\
\end{array}$ & 0 & \begin{tabular}{|l|l}
1 & 1 \\
\end{tabular} & \begin{tabular}{l|l|}
1 & 1 \\
\end{tabular} & 0 & 00 & 0 & 0 & 0 & 0 & 0 & & 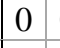 & \begin{tabular}{l|l}
0 & 0
\end{tabular} & 0 & & 0 & 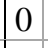 & 1 & 0 & $\begin{array}{lll}0 & 0\end{array}$ & \begin{tabular}{l|l}
0 & 1 \\
\end{tabular} & 1 \\
\hline & & 0 & $\begin{array}{ll}1 & 1 \\
\end{array}$ & 0 & $\begin{array}{lll}0 & 0 \\
\end{array}$ & \begin{tabular}{ll|}
0 & 0
\end{tabular} & 0 & 00 & 0 & 0 & 0 & C & 0 & & 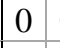 & 0 & 0 & & 0 & & 1 & 0 & 00 & 02 & \\
\hline & & & \begin{tabular}{|l|l}
1 & 1 \\
\end{tabular} & 0 & $\begin{array}{lll}0 & 0 \\
\end{array}$ & \begin{tabular}{|l|l|}
0 & 0 \\
\end{tabular} & 1 & \begin{tabular}{l|l}
1 & 1 \\
\end{tabular} & 0 & 0 & 0 & U & U & 0 & 1 & \begin{tabular}{l|l}
1 & 1 \\
\end{tabular} & \begin{tabular}{l|l}
1 & 0 \\
\end{tabular} & 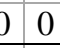 & 0 & 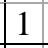 & 1 & 1 & \begin{tabular}{|l|l|}
0 & 0 \\
\end{tabular} & 03 & 3 \\
\hline & & & \begin{tabular}{l|l}
0 & 0
\end{tabular} & 1 & \begin{tabular}{|l|l|}
0 & 0 \\
\end{tabular} & \begin{tabular}{|l|l|}
0 & 0 \\
\end{tabular} & 0 & \begin{tabular}{l|l}
0 & 0 \\
\end{tabular} & \begin{tabular}{l|l|} 
& 1 \\
\end{tabular} & 1 & - & 1 & 1 & & \begin{tabular}{|l|}
0 \\
\end{tabular} & \begin{tabular}{l|l}
0 & 0 \\
\end{tabular} & 0 & & \begin{tabular}{l|}
0 \\
\end{tabular} & & 0 & 1 & \begin{tabular}{|l|l|}
1 & 1 \\
\end{tabular} & \begin{tabular}{l|l|}
1 & 1 \\
\end{tabular} & 1 \\
\hline 7 & $m_{56}$ & $2 / 9$ & $\begin{array}{lll}0 & 0\end{array}$ & 1 & $\begin{array}{lll}0 & 0 \\
\end{array}$ & \begin{tabular}{ll|}
0 & 1 \\
\end{tabular} & 1 & \begin{tabular}{l|l}
1 & 1
\end{tabular} & 10 & 0 & 0 & 1 & 1 & 1 & 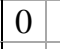 & \begin{tabular}{l|l}
1 & 1 \\
\end{tabular} & \begin{tabular}{l|l}
1 & 1 \\
\end{tabular} & 1 & 1 & 0 & 0 & 0 & 00 & 02 & 2 \\
\hline & & & $\begin{array}{ll}0 & 0 \\
\end{array}$ & & \begin{tabular}{|l|l}
0 & 1 \\
\end{tabular} & \begin{tabular}{l|l|}
1 & 1 \\
\end{tabular} & 0 & $\begin{array}{lll}0 & 0 \\
\end{array}$ & 0 & ) & 0 & & 0 & & 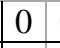 & 0 & & & 1 & & & 0 & \begin{tabular}{|l|l}
0 & 0 \\
\end{tabular} & 03 & 3 \\
\hline & & & \begin{tabular}{|l|l|}
0 & 0
\end{tabular} & 0 & \begin{tabular}{|l|l|}
0 & 0 \\
\end{tabular} & \begin{tabular}{|l|l|}
0 & 0 \\
\end{tabular} & 1 & \begin{tabular}{l|l}
1 & 1
\end{tabular} & 0 & 0 & 0 & 0 & 0 & 0 & 1 & \begin{tabular}{l|l|}
1 & 1
\end{tabular} & \begin{tabular}{l|l}
1 & 1
\end{tabular} & 1 & 1 & 0 & 0 & 0 & \begin{tabular}{|l|l|}
0 & 0 \\
\end{tabular} & \begin{tabular}{l|l}
0 & 1 \\
\end{tabular} & 1 \\
\hline & $m_{66}$ & $3 / 9$ & $\begin{array}{lll}0 & 0\end{array}$ & 0 & $\begin{array}{lll}1 & 1 \\
\end{array}$ & 10 & 0 & \begin{tabular}{l|l}
0 & 0
\end{tabular} & 1 & 1 & 1 & 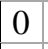 & 0 & 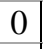 & 1 & \begin{tabular}{l|l}
0 & 0 \\
\end{tabular} & 0 & 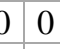 & 0 & 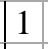 & 0 & 1 & 11 & 12 & 2 \\
\hline & & & \begin{tabular}{l|l}
0 & 0 \\
\end{tabular} & 0 & \begin{tabular}{ll|}
1 & 0 \\
\end{tabular} & \begin{tabular}{|l|l|}
0 & 0 \\
\end{tabular} & 0 & \begin{tabular}{l|l}
0 & 0 \\
\end{tabular} & $\begin{array}{ll}0 \\
\end{array}$ & 1 & 1 & 1 & 1 & 1 & 0 & \begin{tabular}{l|l}
0 & 0 \\
\end{tabular} & \begin{tabular}{l|l}
0 & 0 \\
\end{tabular} & 0 & 0 & 0 & 0 & 0 & \begin{tabular}{l|l}
1 & 1 \\
\end{tabular} & 13 & 3 \\
\hline & & & 44 & & 33 & \begin{tabular}{ll|}
3 & 3 \\
\end{tabular} & 8 & 88 & 36 & 56 & 3 & 6 & 7 & 0 & 8 & \begin{tabular}{l|l}
88 \\
\end{tabular} & \begin{tabular}{l|l}
8 & 8
\end{tabular} & \begin{tabular}{l|l}
8 & 8
\end{tabular} & 8 & 7 & 2 & 75 & 55 & \begin{tabular}{l|l}
5 & 1 \\
\end{tabular} & \\
\hline & $l$ & & $\begin{array}{ll}4 & 4 \\
\end{array}$ & & 89 & \begin{tabular}{ll|}
9 & 8 \\
\end{tabular} & 7 & $\begin{array}{ll}7 & 7 \\
\end{array}$ & 76 & 56 & 4 & 4 & 7 & 4 & 5 & \begin{tabular}{l|l}
76 \\
\end{tabular} & \begin{tabular}{l|l}
6 & 6 \\
\end{tabular} & \begin{tabular}{l|l}
6 & 6 \\
\end{tabular} & 6 & 7 & 2 & 76 & 66 & 62 & $2 \lambda$ \\
\hline & & & 44 & & \begin{tabular}{|l|l}
8 & 7 \\
\end{tabular} & \begin{tabular}{ll|}
7 & 7 \\
\end{tabular} & 5 & 55 & 56 & 56 & 4 & 7 & 8 & 7 & 2 & \begin{tabular}{l|l}
54 \\
\end{tabular} & \begin{tabular}{l|l}
4 & 6 \\
\end{tabular} & $\begin{array}{ll}6 & 6 \\
\end{array}$ & 6 & $\perp$ & 2 & 4 & 66 & $\begin{array}{ll}6 & 3 \\
\end{array}$ & 3 \\
\hline & .7 & & & & S & Sin & & & & $\mathrm{N}$ & & & 1 & & $\mathrm{a}$ & de $E$ & Estab & b & $\tilde{\tau}$ & & $\lambda: 1$ & $-\mathrm{Nc}$ & Toroes & este & \\
\hline & & & & & $\mathrm{T}$ & Га & & & & & & & 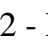 & & A & Ativa & & & & & 2 & - $\mathrm{Ce}$ & entro & O_I & cou \\
\hline & & & & & & & & & & & & & & & & & & & & & $\lambda: 3$ & $-\mathrm{Su}$ & & & \\
\hline
\end{tabular}

\section{REFERÊNCIAS}

ABGE - ASSOCIAÇÃO BRASILEIRA DE GEOLOGIA DE ENGENHARIA E AMBIENTAL. Geologia de Engenharia. São Paulo: ABGE, 1998, p. 587.

BENSUSAN, N. Conservação da biodiversidade em áreas protegidas. Rio de Janeiro: FGV, 2006, 176p.

BRAGA, A. Critérios de Escoamento. Rio de Janeiro: Pontífice Universidade Católica, 2010, 15p.

BRESSANE, A.; REIS. F.A.G.V.; GIORDANO, L.C; 
ROVEDA, S.R.M.M.; MARTINS, A.C.G.; ROVEDA, J.A.F. Construção de um índice global de impacto para análise ambiental comparativa aplicada à adequação de empreendimentos irregulares. Revista Engenharia Sanitária e Ambiental, v. 22, n.1, 2017.

CETESB - Companhia AMBIENTAL DO ESTADO DE SÃO PAULO. Manual técnico de avaliação de desempenho de estações de tratamento de esgoto. São Paulo: CETESB, 1989, 58p.

CPRM - SERVIÇO GEOLÓGICO DO BRASIL. GEOBANK Litoestratigrafia. Disp. em: < http://geobank.cprm.gov.br/ > Acesso em: 06 abr. 2016.

IBGE. INSTITUTO BRASILEIRO DE GEOGRAFIA E ESTATÍSTICA. Manual Técnico de Pedologia. 2ed. Rio de Janeiro: IBGE, 2005, 300p.

KRONKA, F.J.N.; NALON, M.A.; MATSUKUMA, C.K. Inventário florestal da vegetação natural do Estado de São Paulo. São Paulo: Secretaria do Meio Ambiente/Instituto Florestal, 200p., 2005

LEPSCH, F.I. Formação e conservação dos solos. São Paulo: Oficina de textos, 2002, 178p.

MONTEIRO, C.A.F. A dinâmica climática e as chuvas no estado de São Paulo. São Paulo: IGEOG-USP, 1973, 129p.

NAVAL, L.P.; BARROS, D.S.B.; SILVA, C.D.F. Aplicação de métodos de avaliação de impactos ambientais a uma ETE operando em escala real com a respectiva proposição de medidas mitigadoras. 2004. Disp. em: $<$ http://www.bvsde.paho.org/bvsAIDIS

/PuertoRico29/danger.pdf > Acesso em: 06 abr. 2016.

OLIVEIRA, F.C. \& MOURA, H.J.T. Uso das metodologias de avaliação de impacto ambiental em estudos realizados no Ceará. Pretexto, v. 10, p. 79-98, 2009.

OLIVEIRA, J.B; CAMARGO, M.N.; ROSSI, M.; CALDERANO FILHO, B. Mapa Pedológico do Estado de São Paulo. Campinas: IAC/EMBRAPA, 1999, 64p.

PRIMACK, R.B. \& RODRIGUES, E. Biologia da conservação. Londrina: Efraim, 2002, 328p.

RAMOS, A.R. Sistema de gestão ambiental em estações de tratamento de esgoto. O caso da ETE Remédios. São Carlos. 2004. 148p. Dissertação (Mestrado Engenharia Urbana), Universidade Federal de São Carlos.

ROCHA, G. (Org). Mapa de águas subterrâneas do Estado de São Paulo. São Paulo: DAEE/IG/IPT/CPRM, 2005, 119p.

ROCHA, C. Proposta para o gerenciamento da estação de tratamento de esgotos Jarivatuba - ETE-Jarivatuba, Joinville, SC. Florianópolis, 2005. 110p. Dissertação (Mestrado em Engenharia Ambiental). Universidade Federal de Santa Catarina.

RODRIGUES, R.R. \& BONONI, V.L.R (Orgs). Diretrizes para a Conservação e Restauração da Biodiversidade no Estado de São Paulo. São Paulo: FAPESP, 2008, 248p.

ROSS, J.L.S. Geomorfologia aplicada aos EIA-RIMAS. In: GUERRA, A.J.T.; CUNHA, S.B. (Org.). Geomorfologia e meio ambiente. 3ed. Rio de janeiro: Bertrand, 2000. p. 291336.

ROSS, J.L.S. \& MOROZ, I.C. Mapa Geomorfológico do Estado de São Paulo. v. 1, São Paulo: FFLCH-USP / IPT / FAPESP, 64p., 1997

SCALIZE, P.S.; SITA, W.; LEITE, W.C.A. Desempenho de uma ETE pelo processo de lodos ativados operando por batelada. In: EXPOSIÇÃO DE EXPERIÊNCIAS MUNICIPAIS EM SANEAMENTO, 7, 2003, Santo André. Anais... Santo André: ASSEMAE, p. 1-9.

SÁNCHEZ, L.E. Avaliação de impacto ambiental: conceitos e métodos. São Paulo: Oficina de Textos, 2006, 496p.

SANTOS, F.S. Planejamento ambiental: teoria e prática. São Paulo: Oficina de Textos, 183p. 2004

TROPPMAIR, H. Biogeografia e meio ambiente. 8ed. Rio Claro (SP): Divisa, 2008, 227p.

VAZ, A.P.R. \& DUCATTI, M.L. Avaliação de Impactos Ambientais na Estação de Tratamento de Esgoto Sanitários: ETE - Lajes, Aparecida de Goiânia-GO. Goiânia, 2003. 16f. Monografia. (Especialização em Gestão Ambiental). SENAI / UCG. Goiânia.

VON SPERLING, M.V. Princípios do tratamento biológico de águas residuárias: princípios básicos do tratamento de esgotos, v. 2, Minas Gerais: UFGM, 245p., 1996.

Submetido em 3 de maio de 2016 Aceito em 4 de outubro de 2017 